unison with the sunspot periods, at all events enough to warrant further and more complete investigations being made on the point. I will not trespass on your valuable space further than to add a similar rough indication of the inverse relation that holds in the case of the summer rainfalls. They will be seen to be greatest in years of maximum sunspot.

In the following groups the rainfall of Dehra is taken for the months of June, July, August, September, and October during which the south-west mons'on rains fall. I give the separate rainfall during these months for each year, as well as the totals and averages.

\begin{tabular}{|c|c|c|c|c|c|}
\hline \multicolumn{3}{|c|}{ Maximum sun-spot groups. } & \multicolumn{3}{|c|}{ Minimum sun-spot groups. } \\
\hline Years. & Inches. & Tutals. & Years. & Inches. & Totals. \\
\hline $\begin{array}{l}186 \mathrm{I} \\
\mathrm{I} 862\end{array}$ & $\left.\begin{array}{l}9 r^{\prime} 4 \\
90.5\end{array}\right\}$ & I $8 I \cdot 9$ & $\begin{array}{l}1875 \\
\text { I } 876\end{array}$ & $\left.\begin{array}{l}67 \cdot 2 \\
76 \cdot 1\end{array}\right\}$ & $143^{\circ} 3$ \\
\hline \multicolumn{2}{|c|}{ Average for each year } & 90.9 & \multicolumn{3}{|c|}{ Average for each year 716} \\
\hline $\begin{array}{l}\text { I } 869 \\
\text { I } 870 \\
\text { I } 871\end{array}$ & $\left.\begin{array}{r}70 \cdot 5 \\
77 \cdot 2 \\
100 \cdot 2\end{array}\right\}$ & $247^{\circ} 9$ & $\begin{array}{l}\text { I } 865 \\
\text { I } 866 \\
\text { I } 867\end{array}$ & $\left.\begin{array}{l}58 \cdot 9 \\
67 \cdot 0 \\
60 \cdot 6\end{array}\right\}$ & $186 \cdot 5$ \\
\hline \multicolumn{2}{|c|}{ Average for each yea } & $82 \cdot 6$ & \multicolumn{3}{|c|}{ Average for each year $62 \cdot 1$} \\
\hline
\end{tabular}

The averages give a mean average excess in each year in the maximum sun-spot groups of 19.9 inches over each year in the minimum groups ; a givantic difference certainly, and apparently maintained pretty consistently throughout by the rainfall of each year. The defect in the winter rainfall of years of maximum sunspot and the corresponding excess in years of minimum sunspot together combine to render the excess in years of maximum sun-snot less apparent in the toral annual falls, though it still exists to a certain extcnt. The present year (at present abnormaily ieficient in solar activity) appears destined to fulfil the preceding relations to an alarming extent. The winter rainfall was unt:ually plentiful throughout Norchern India, while, up to the present time, when the monsoon should be in full swing, the rains, except in Eastern Bengal, have been so scanty that unless rain falls soon and abundantly, we shall have to face a farrine as fearful as that which is just now devastating Madras.

E. D. ARCHIBALD

\section{Greening of Oysters}

It has long been known that oysters, when removed from the sea and kept artificially in shallow pits filled with salt.water, assume a green colour which is or was much thought of by epicures. While this spring at Le Croisic, at the mouth of the Loire, my friend, Dr. Bornet, informed Prof. Lankester and myself that this singular change was particularly observable in the oyster preserves in the neighbourhood. He was at that time at a lo.s for an explanation, but I have just received a letter from him in which lie gives the solution of the problem, and this will I think be so interesting to many of the readers of NATURE, that I have ventured, although without his permission, to communicate it to them.

"As a souvenir of our meeting at Croisic, I send you some Corallinaceze from that locality. Several have not yet been detected on the English coast, where, however, they ought to occur. I have added a Diatom, Navicula fusiformis, Grunow, var. ostrearit. 'This species, whose contents are of a cobalt-blue colour during life, occurs in profusion in the oyster-preserves of Croisic, and it is because they feed on this Diatom that they become green. Nothing is easier than to demonstrate the fact by placing white oysters in a plate of sea-water containing nothing but Naziculli fusiformis, and the "greening" takes place in thirty-six hours. As often as the experiment is repeated, the same result follows. But why should Navicula fusiformis be blue, while all other Diatoms are culourless?"

W. T. Thiselton Dyer

P.S.-Since this note has been in type Prof. Oliver has called my attention to a paper in the "Mémoires de la Société Linncéene du Calvados," I\$24, pp. 135-158, by Benjamin Gaillon, "Sur la cause de la colcration des Huîtres et sur les Animalcules qui servent à leur nutrition." These animalcules form masses which he compares to the green matter of Priestley, and as he refers them to the genus Navicula of Bory, they are no doubt identical with those which Dr. Bornet has studied. Gaillon refers to an earlier memoir of his own on the same subject published by the Academy of Sciences of Rouen, and in the Annales des Sciences Physiques, for $182 \mathrm{I}$. W. T. T. D.

\section{Reproduction by Conjugation}

THE phenomenon to which Mr. Bennett alludes is, I presume, well known; but it is not universal, though common. He will fird illustrations in Hassall's "British Freshwater Algæ," where the zygospores aie formed in both filaments simultaneously; e.g., plate I9, Zygnema (Spirogyra); plate 38 , several species of Tyndaridea. But in those genera in which the Zygospore is formed between the filaments it would seem impossible to decide which is male and which is female, e.g., plate 39, Tyndaridea conspicua, immersa, Ralfsii, and decussata; or in the genera Mesocarpus, plates 42-47, and Stenocarpus, plates $47-49$.

\section{GEORGE HENSLOW}

\section{Strange Dream Phenomenon}

AFTER reading the interesting letter on a "Strange Dream Phenomenon" which appeared in NATURE (vol. xvi. p. 329) it occurred to me that it might be worth while to put on recurd the following experience which connects in a very striking manner the phenomena of dreaming and subjective vision. Sime time ago, when rather tired by overwork, I dreamt during the night that some one had entered my bedroom and was approaching the pillow under my head with the intention of abstracting some valuable papers which I fancied were concealed beneath it. I noticed in every particular the dress, stature, and features of the intending robber, but just as he put furward his hand towards the bed I began to awake, slowly at first, but with great celerity as soon as I perceived the figure of my dream walking slowly duwn the side of the bed; wide awake now, $I$ watched it reach the corner bedpust, turn round, and with. measured noiseless step pass along the foot, till on coming between the window and myself it disappeared, as all the "ghosts" with which I was then afflicted were wont to do when shone through by the light.

I did not sleep any more for the rest of the night, and hence arn perfectly certain that this was not "a drem within a dream," but a clear case of a subjective vision prolonged from the sleepng into the waking state, and thus affurding evidence to prove the essential identity which underlies the phenomena of "dream. ing dreams" and seeing "ghosts." W. J. S.

\section{OUR ASTRONOMTCAL COLUMN}

THE SATELlites OF MARs.-The Paris correspondent of the Times, writing on August 27, states that at the meeting of the Academy of Sciences the same day, M. Faye had announced the independent discovery of the satellites of Mars by M. Borrelly at Marseilles, clauming for him even an earlier detection than was effected at Washington. Prof. Watson's name being introduced as the American discoverer instead of that of Prof. Asaph Hall, it is clear that the statement has arisen from a misconception on the part of the reporter at the sitting of the Academy, who has confounded the discovery of No. 174 of the minor-planet group, by Watson and Borrelly, with that of the satellites of Mars.

A letter from Rear-Admiral Rodgers, Superintendent of the Naval Observatory, Washington, to the Secretary of the Navy, dated August 2 I, furnishes particulars of the observations and calculations bearing upon both satellites, which had been made up to that date. The outer satellite was remarked on the $I I t h$, but its true character was not certainly recognised until the 16th. On the following night Prof. Hall first observed the inner satellite. The discoveries were telegraphed to Messrs. Alvan Clark and Sons, at Cambridyeport, on the I8th, that confirmatory evidence of the existence of the satellites might be obtained by means of the 26 -inch telescope of Mr. McCormick, at present in the hands of those eminent opticians, who succeeded in verifying Prof. Hall's discovery, as did also Prof. Pickering and his assistants at Cambridge, Mass. On the Igth the discovery was 
communicated to the Smithsonian Institution, and by it, to the European observatories.

We subjoin the principal results of Prof. Newcomb's calculations on the first ten days' measures, extracted from a circular for which we are indebted to the superintendent of the U.S. Naval Observatory.

For the outer satellite Prof. Newcomb finds :- -

Major axis of apparent orbit at clistance [9.5930] ...

Minor axis

Maior axis of orbit at distance unity...

Pasition angles of line of apsides of apparent Passage through west apsis $\left(p=250^{\circ}\right) \ldots$ Aug. 19 at $16 \mathrm{~h} \cdot 6$ W.M.T. Inclination of true urbit to the ecliptic $\ldots \begin{array}{lllll}\ldots & \ldots & \ldots & \ldots & 25^{\circ} \\ 4\end{array}$

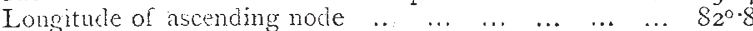

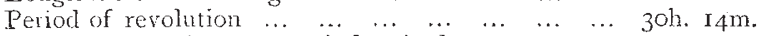

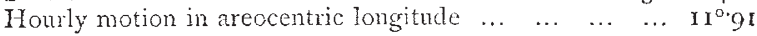

These elements give for the mass of Mars

For the inner satellite Prof. Newcomb finds-

Najor axis of apparent orbit at distance [9.5930]

Passace through eastern apsis $\left(p=70^{\circ}\right)$... Ang. 20 .t 13 h o IV M.T.

Period of revolution

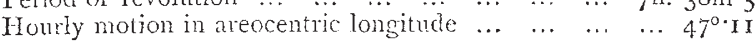

If we refer the position of the orbit of the first satellite to the earth's equator, the ascending node will be found to be in $46^{\circ} 4$, and the inclination $36^{\circ} \cdot 2$. The real distances of the satellites from the centre of Mars are about 14,500 and 5,800 miles respectively.

Prof. Newcomb, writing to the New York Tribune on August 22, gives some particulars relating to the new satellites. He remarks that the first question which will naturally arise is, Why have these objects not been seen before? The answer is that Mars is now nearer to the earth than he has been at any time since 1845 , when the great telescopes of the present day had hardly begun to be known. In I 862 when Mars was again pretty near to the earth, we may suppose that they were not looked for with the two or three telescopes which alone would have showr thern. In 1875 Mars was too far south of the equator to be advantageously observed in these latitudes. The present opportunity of observiny the planet is about the best that could possibly occur. At the next opposition in October, 1879 , there is hope that the satellites may be again observed with the great telescope at Washington, but Prof. Newcomb thinks that during the following ten years, when owing to the great eccentricity of the orbit of Mars, he will be much further from the earth at opposition, the satellites may be invisible with all the telescopes of the world. In the present year it is hardly likely that they will be visible after October. The satellites may be considered as by far the smallest heavenly bodies yet known. "It is hardly possible to make anything like a numerical estimate of their diameters, because they are seen in the telescope only as faint points of light. But one might safely agree to ride round one of them in a railway car between two successive meals, or to walk round in easy stages during a very brief vacation. In fact, supposing the surface of the outer one to have the same reflecting power with that of Mars, its diameter cannot be much more than ten miles, and may be less. Altogether these objects must be regarded as among the most remarkable of the solar system." Prof. Newcomb further points out that we may regard M. Leverrier's mass of Mars as the product of a century of observation, and several years of laborious calculation by a corps of computers, while from the measures on four nights of the new satellites, ten minutes' computation gives a mass which is in striking agreement with that of the illustrious astronomer of Paris.

THE D'ANgos COME'T OF I 784.-In continuation of our remarks upon this object, so long considered apocryphal
(NATURE, vol. xvi. p. I24), we proceed to notice an investigation by D'Arrest, undertaken in 1865 . He refers to a somewhat confused note in Cooper's "Catalogue of Cometic Orbits," where the orbit given by D'Angos is introduced " with no slight misgivings," though the writer thought his note was "considerably opposed to Encke's statement," on what precise grounds, however, is not very apparent. And D'Arrest considered the essay in Zach's work may have reccived undue colouring from the editor, and a further proof of the non-existence of the comet is required.

Deducing the sun's places from the Tables of Hansen and Olufsen, D'Arrest compares the fourteen days' observations given by D'Angos in Bernouilli's and Hindenburg's Magazine, with the best of two orbits calculated by Olbers from them, and finds what he terms "horrenden Abweichungen." A similar comparison by means of elements selected from numerous sets computed by himself, exhibits also great differences, so that his first conclusion is identical with that arrived at by Olbers and Encke, the comet's places are irreconcilable with parabolic motion about the sun. On applying the general method of the Theoria mntus he was led to extraordinarily small distances from the earth, in perfect agreement with the results obtained by Encke on a different method of procedure.

D'Arrest then introduces the consideration of the geocentric hypothesis. We are certain of cases where the orbits of comets have undergone an entire change through the action of the planet Jupiter, and there is now, he urges, no difficulty in accepting the idea of an insignificant and small vaporous mass, passing with a retrograde motion in such close proximity to the earth, that the case treated of in the "Mécanique Céleste," book ix. chap. ii., may enter. The question is a complicated one, and D'Arrest contents himself with examining whether in the series of observations of the comet, there is anything to contradict the hypothesis that for a time it was moving as a satellite of the earth. Necessarily omitting parallax, he finds on this geocentric assumption the following elements :-Time of passage by the perigee, April I $5^{\circ}$ I 3649 mean time at Paris; ascending node $90^{\circ} 52^{\prime} 9^{\prime \prime}$; inclination $43^{\circ} 8^{\prime} 23^{\prime \prime}$; distance of perigee from ascending node $128^{\circ} 7^{\prime} 59^{\prime \prime}$; eccentricity 0.97320 , and least distance from the earth in units of the semi-axis major of the moon's orbit 3.82290 ; motion, retrograde. When now the comet's distances from the earth are found from the observed angular motions, and again direct from the elliptical elements, a comparison shows that the angular motion with respect to the earth corresponds well with the law of areas, and the latitudes from this approximate calculation are sensibly better represented, than on the supposition of heliocentric motion.

The general conclusions arrived at by D'Arrest from his investigation appear to be these: that the impossibility of the observations published by D'Angos and the obvious imposition previously attributed to him are not in accordance with evidence. The comet may have been moving for a time virtually as a satellite of the earth, or while passing very rear to it may yet have been without the sphere of attraction, the definition of which is perhaps somewhat arbitrary. The difficulty and uncertainty attending further research, and the expense of time and labour necessary, induced D'Arrest to rest satisfied with having thrown a more satisfactory light on the observations of the second comet of 1784 , or at least of proving that a small body moving under certain conditions might have occupied the positions in the heavens attributed to it. We have yet to give some account of a paper by Gauss on this subject.

THE FIRST COMET OF I 877 (BORRELLY, FEBRUARY 8) -The elements of this comet, so far as yet published, appear to depend upon an interval of observation of eight 
days only. The following orbit by Mr. Hind is founded on positions between February 8 and March II :-

Perihelion Passage, IS77, January 19.18369 , G.M.T.

Longitude of Peribelion $\ldots \ldots$
Ascending No

There seems to be no sensible deviation from the parabola.

\section{BIOLOGICAL NOTES}

NEW WORK ON BIRDS.-We have received the prospectus of a new. work by Dr. A. B. Mayer, Director of the Royal Zoological Museum of Dresden, to be entitled "Abbildungen von Vogel-Skeletten," in which he signifies his intention to publish, in parts, fisures of the skeletons of rare or little-known birds. Fiach part is to contain ten plates of large quarto size, one of which, representing the skeltton of the extremely uncommon parrot from New Guinea, Dasypthlus pecqueti (Lesson) accompanies the prospectus. It is a pholo-lithograph, and differs materially from any other which we have seen in one important particular, namely that the bones of one side only are depicted, which is a great advantage, as it prevents the confusion unavoidably associated with the representation of the whole structure. The illumination of each bone and the focus of every part is most satisfactory, more so in many respects than any dirawing could possibly be. Short commentaries, with measurements, will accompany each plate. It is proposed that Part I. shall contain figures of Ioriculus cumaissi, Charmosyna josephince, Merofogon forsteni, Paradiser tapnana, Cacnumos regius, Manincoatia charyber, Ptilopius spiciosus, Otidiptraps nobilis, and Gallus bachiva (from Celebes). In the series is also to be included the skeletons of the several domestic pigeons and fowls. We hope that Dr. Mayer will have a large subscription to this valuable addition to ornithological literature.

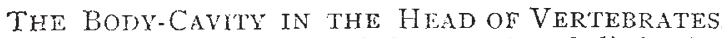
- It has hitherto been regarded as a point of distinction between the mouth, throat, and gill region of vertebrates, and the rest of the trunk, that in the former no splitting of the body wall took place in early development, while in the trunk the body-wall becomes sharply separated from the contained viscera, and a cavity arises between them, part of which is the peritoneal cavity. Mr. Balfour (Fowr. Anat., April, 1877) has announced the discovery in sharks of a head-cavity on either side of the throat, dividing the growing tissue into an inner and an outer wall. When the visceral clefts (future gill-slits, \&c.) appear, they subdivide these cavities into smaller ones. The head-cavity even grows forwards as far as the eye, and ultimate ty there is a series of cavities: (I) a premandıbular, (2) a mandibular, (3) a hyoid, (4) a series in the branchial arches. These cavities ultimately atrophy, but their walls become developed into muscles, and they answer to the muscle-plates of the rest of the body. Thus this discovery gives iniormation of a most valuable kind as to the segmental relations of the head to the rest of the body, besides furnishing a glimpse of a prinordial condition in vertebrates which had till now remained unknown.

FISH-EATING BIRDS.-Mr. Joseph Willcox has recorded an interesting observation on the crow blackbirds of Florida (Quiscalus purpureus). Standing on the bank of a river in Florida, he noticed a commotion among a congregation of crow blackbirds, which were anxiously looking into the water. A large bass was pursuing its favourite food, the smali fry, and the latter, in their frantic efforts to escape, jumped out of the water, and many of them fell on the land. The blackbirds, evidently experts at the game, immediately pounced upon the small fish, and swallowed them before they could get back into the water. (Proc. Acad. Nat. Sci., Phil ${ }^{2}$ delphia. I 877.)

AnTs' DOMEstic Animals.-Prof. Lhidy (Philarelphia) has observed colonies of $F$. flava in possession of several kinds of insects at once. A comparatively small assemblage of them had three groups, an aphis, a coccus, and the larva of an insect, apparently coleopterous. The aphides were kept in two separate herds, and these were separated from a herd of cocci. In a larger colony of ants there was a collection of aphides occupying the under part of one margin of a stone, for ten inches long by three-quarters of an inch wide. A distinct group of cocci, closely crowded, filled a square inch. They all appeared to be carefully attended to by the ants.

A Whale in the Mediterranean.-M. P. J. Van Beneden has made a short communication to the Académie Royale de Belgique, published in that Society's Bulletin, with reference to a letter by M. Capellini, on a true whale captured in the Mediterranean Sea, near Taranto. The Italian author suggests the new sperific name Balcena tarantina, but M. Van Beneden much more reasonably thinks it most probable that it is a stray specimen of $B$. biscayensis.

\section{THE LATE MR. GASSIOT}

WE last week announced briefly the death of Dr. $\mathrm{J}$ P. Gassiot, and now give some account of the princioal scientific results obtained by him. Mr. Gassiot, partner in the firm of Martinez Gassiot and Co., wine merchants, Mark Lane, first devoted his spare time to electrical experiments about the year 1838 . An Electrical Society was formed about that time in which he took an active part. At one of the meetings it was observed that when the two copper wires forming the poles of a powerful voltaic battery were crossed and drawn asunder so that the voltaic arc passed between them, the positive terminal became heated to incandescence, while the negative remained comparatively cool. This excited great interest in Mr. Gassiot's mind and led him to make several experiments, but without thoroughly explaining the phenomenon. In the course of these experiments he procured powerful batteries, first of Daniell's construction, then of Grove's, and ultimately a large water battery.

It had been observed by many writers (principally Continental) that while the dynamic and chemical effects of the voltaic battery increased in intensity in proportion to the increasing chemical action in the cells of the battery, the static effects, such as the repulsive action in a gold leaf or pith ball electroscope, the spark, the power of charging a Leyden phial, \&c., were more intense when the battery was charged with water and had consequently but a feeble chemical action in the cells. This anomaly puzzled electricians much, and though sought to be explained by various hypotheses, was a great stumblingblock in the way of the chemical theory of the voltaic battery.

Mr. Gassiot had been led to attach great value to good insulation between the cells of the battery, and he procured to be made a Grove battery (the most powerful chemical battery known) of roo glass cells, all having long glass stems, and separated from each other. This battery gave very powerful chemical results, and a voltaic arc of great brilliancy; but, what was of the greatest importance, he found that with this battery the static effects, or effects of tension, were greater than those of an equally-sized water battery. The puzzling anomaly was thus explained ; the reason why the chemical battery had seemed inferior in tension to the water battery was that from the effervescing liquids, the close approximation of 